\title{
A TRAJETÓRIA DE VIDA DA EDUCADORA PETRONILHA BEATRIZ GONÇALVES SILVA
}

\author{
SILVA, Petronilha Beatriz Gonçalves. Entre Brasil e África: Construindo Conhecimento e \\ Militância. Belo Horizonte-MG. Editora Mazza, 2011.
}

Resenhado por:

Glaziela Aparecida Franco ${ }^{1}$

Manoel Nelito Matheus Nascimento ${ }^{2}$

O livro "Entre Brasil e África: construindo conhecimento e militância" de Petronilha Beatriz Gonçalves e Silva apresenta a sua trajetória de vida, "[...] com o propósito de expor caminhadas que tenho empreendido e com a esperança de que elas inspirem outras jornadas." (p. 160). O livro reúne reflexões e recordações do ambiente familiar, da formação escolar, da vida profissional e das militâncias social e política, que estão entrelaçados ao contexto histórico da sociedade brasileira nas últimas décadas.

Petronilha iniciou a docência como professora de Português e Francês, fez mestrado e doutorado em Educação e em 1989 ingressou como docente na Universidade Federal de São Carlos (UFSCar), onde tornou-se Professora Titular em Ensino-Aprendizagem - Relações Étnicorraciais. Em 2012 aposentou, quando lhe foi outorgado o título de Professora Emérita da UFSCar. No período de 2002 a 2006, foi Conselheira da Câmara de Educação Superior do Conselho Nacional de Educação (CNE), por indicação do Movimento Negro. No CNE foi relatora do parecer sobre a Lei 10.639/2003, que estabelece a obrigatoriedade do ensino de História e Cultura Afro-Brasileira e Africana na Educação Básica.

O livro está organizado com uma introdução intitulada de "Começo de conversa" e dez capítulos que abordam desde os anos iniciais de vida às experiências dos anos recentes que consolidam sua riquíssima trajetória de vida, chegando ao apropriado título do livro e de um dos capítulos: "Entre Brasil e África: construindo conhecimento e militância".

Petronilha se apresenta como mulher negra, professora, pesquisadora e militante político-social, isto é, uma verdadeira intelectual orgânica, reconhecendo que "minha negritude, isto é, a construção de meu pertencimento racial, foi incentivada no meio da minha família: todos nos sabíamos negros, dos mais escuros aos mais claros, e gostávamos de sê-lo." (p. 14). E diz que vai se fazendo "mulher negra em todas as dimensões da vida que busco e que me são dadas viver" (p. 13).

No primeiro Capítulo "Nasci e cresci", a autora rememora o lugar onde nasceu, na Rua Esperança, em uma Colônia Africana, em Porto Alegre. Os livros e as aulas sempre estiveram presente na sua infância porque sua mãe era professora da rede pública estadual, onde lecionou por 41 anos, sendo a primeira professora negra a receber o título de Professora Emérita do Estado do Rio Grande do Sul. Aos seis anos e meio de idade foi matriculada no Grupo Escolar Uruguai, na mesma rua onde morava. Posteriormente continuou os estudos no Colégio Aplicação da Faculdade de Filosofia da URGS. Lembra que no primário tinha um bom número de colegas negros, porém no Colégio Aplicação reduziu para apenas três alunas negras e do colegial em diante nas classes em que cursou não teve mais colegas negros.

No Capítulo "Fontes e Caminhos", a autora narra a sua formação escolar no ensino superior. Cursou Letras Neolatinas na Faculdade de Filosofia da URGS, onde colou grau em 1964 em Letras - Português e Francês. Relata sua experiência na universidade, em 1963, quando houve uma reforma universitária que extinguiu os cursos de Neolatinas, AngloGermânicas e Clássicas e criou o curso de Letras, que formava para licenciatura em Português 
e uma língua estrangeira. Logo ela optou por Francês, no qual passou a aprimorar a aprendizagem da língua francesa e completou seus estudos na Aliança Francesa.

Em "Tornando-me professora" a autora recorda que foi se educando professora desde sua infância, pois observava a sua mãe lecionar aulas particulares, preencher diários, corrigir trabalhos e também ouvia conversas de suas amigas professoras, pois várias expressavam as dificuldades, os baixos salários e também as alegrias da profissão. E a partir destas observações a autora notou que havia poucas professoras negras, e que desde o ensino primário até chegar ao doutorado, nunca teve a oportunidade de ser aluna de um professor negro.

No terceiro ano de faculdade, Petronilha começou a lecionar Português, no curso ginasial do Ginásio Comercial Antão de Faria, localizado em Porto Alegre. Nesta experiência, ela foi professora de meninos e meninas de 12 anos e também de seus pais. Todos os seus alunos trabalhavam o dia todo e estudavam a noite, alguns não aguentavam o cansaço e dormiam na aula. Logo a maioria de seus alunos eram negros. Portanto nota-se que começo de sua vida profissional foi em um ambiente de pura diversidade, de relações étnico-raciais, de gênero e entre gerações, numa mesma sala de aula. Em 1972, ela assumiu sua primeira função no Ensino Superior como professora horista, para ministrar a disciplina de Língua Portuguesa: Habilidades de Linguagem Escrita, na Universidade Federal do Rio Grande do Sul, atividade que desempenhou até 1976. A autora também foi docente na PUC/RS, em um curso de especialização em Supervisão Escolar e também iniciou o trabalho de orientadora de dissertações e teses, ministrando aulas na Pós-Graduação em Educação.

No ano de 1989, Petronilha prestou concurso e ingressou no Departamento de Metodologia de Ensino da (UFSCar), onde tem atuado como docente e pesquisadora no curso de Pedagogia, no Programa de Pós-Graduação em Educação e em cursos de extensão universitária, na maioria todos esses estudos são promovidos pelo Núcleo de Estudos AfroBrasileiros (NEAB).

O capítulo "As salas de aula vêm sendo universos que se abrem para outros" relata o tempo em que foi professora de Francês no Colégio Aplicação, onde todos os professores eram incentivados a desenvolver experiências pedagógicas.

No capítulo "Assim fui me fazendo pesquisadora" expõe a formação no mestrado em Educação, na área de concentração em Planejamento de Sistemas de Ensino do PPGE da Universidade Federal do Rio Grande do Sul (UFRGS), quando despertou para os problemas técnicos e políticos em educação. Sobre o doutorado realizado no PPGE/UFRGS, ela relata que foi uma oportunidade ímpar para desembaraçar conhecimentos já explorados e procurar entrelaçá-los, no mais documentado possível no estudo dos livros e da vida.

Em "Profissão e militância" reflete sobre as demandas e as propostas do Movimento Negro para a luta antirracista e a afirmação cidadã dos negros em todos os âmbitos da vida social. Petronilha relata a realização no meio acadêmico, na década de 1980, das primeiras pesquisas na área da educação na perspectiva e interesse dos negros, elaboradas pelos militantes.

O capítulo "Aprendendo-ensinando-aprendendo" a autora revela que os alunos com as suas aprendizagens e pesquisas tornaram-se parte das suas alegrias, dificuldades e também fortes de energia e justificativa para as suas realizações como docente e pesquisadora. Ela conta ter recebido uma contribuição importante para seu jeito de ensinar de um grupo de jovens que cursavam a Habilitação Magistério. As alunas incentivadas pelas discussões na União e Consciência Negra, "escreveram para seus professores que observassem seus braços levantados, pois estavam querendo participar dos debates, que não desconhecessem que eram negras e as apoiassem na construção de seu pertencimento étnico-racial" (p. 109). A partir 
desta experiência, ela começou a inquirir quais seriam as especificidades de cada um de seus alunos que quereriam evidenciar e reforçar e para tanto, precisariam do seu apoio.

No capítulo "Educação das relações étnico-raciais e ações afirmativas", Petronilha chama a atenção para a responsabilidade de mulheres e homens negros e também dos não negros, no combate ao racismo, em todos os âmbitos da sociedade, inclusive nas escolas. Observa ser seu desejo e também dos afrodescendentes, ver a história e a cultura do povo negro incluída nos currículos escolares, e também a implantação de políticas reparatórias e de ações afirmativas.

Ela ainda afirma ter sido possível conjugar as lidas da vida, da profissão e da militância, com o trabalho compartilhado, a troca de informações, a contribuição mútua, a participação de atividades científicas e políticas. Também tem a ajudado combater a desesperança diante dos efeitos cruéis do embranquecimento de mentes, da fuga das raízes africanas para tentar sobreviver com menos dor, numa sociedade que sempre rejeitou os negros.

Ressalta, o que tem "aprendido e realizado é fruto do convívio com meus alunos, da companhia da comunidade negra, dos parentes, amigos, professores - tanto dos que foram meus mestres, como dos que são meus colegas." (p. 135). Convívio que proporcionaram riquíssimas experiências e conhecimentos sobre a educação das relações étnicorraciais e as políticas de ações afirmativas.

Em 2006, ela participou da criação do programa de reserva de vagas para estudantes de escola pública, para negros e para indígenas da UFSCar, quando assumiu a a coordenação do Grupo Gestor do Programa de ações afirmativas. Ela destaca a importância do programa e observa que "em outras palavras, obrigou-me a passar das ideias e propostas para a ação." (p. 139)

No capítulo "Entre Brasil e África: construindo conhecimento e militância", a autora chama a atenção para o sofrimento de crianças negras diante do tratamento recebido em escolas, à discriminação sofrida por homens negros confundidos por malfeitores, a dor de mulheres negras quando reduzidas a símbolo sexual e tantas outras formas de desumanizar o povo negro. Para ela, essa realidade mostra a urgência de buscar nas raízes africanas, na história dos antepassados, para conhecer e divulgar os pensamentos dos negros sobre quem consideram pessoas educadas, sobre as condições que avaliam necessárias para a formação e educação de homens e mulheres cidadãos. A autora afirma que enquanto docente e pesquisadora têm sido incentivada a buscar teorias da educação que informem o "ideal de educação para todos", numa perspectiva do povo diverso, integrante da sociedade multicultural que é a brasileira,

O encontro entre Brasil e África é relatado nas experiências e aprendizados do pósdoutorado realizado na University of South Africa (UNISA) em Pretoria em 1996, quando surpreende-se com coincidências com o que aprendera na família, no Limoeiro e entre os negros de Santa Cruz do Sul/RS. (p. 149).

No último capítulo do livro "Caminhando sempre", Petronilha faz uma reflexão sobre a sua caminhada junto com pessoas do Brasil, de outras diásporas e da África. Diz compreender cada vez mais o quanto caminhar é indispensável para viver, apesar das incertezas destes caminhos. Pois "quem caminha tem palavra, caminhar exige mudar de lugar, ensina a compreender o mundo, a grande escola" (p.160).

Para concluir o livro, Petronilha expõe "algumas sendas e sinalizações" que têm orientado sua trajetória de vida, como: 
“[...] promover, incentivar relações étnico-raciais que valorizem igualmente a todos, é preciso desmontar hierarquias, mitos, histórias que cultivem sentimentos de superioridade, de inferioridade." (p. 161).

"[...] para as populações mantidas à margem pela sociedade, não basta ocupar bancos nas salas de aula das escolas e universidades, se tiverem de esconder ou negar seu pertencimento étnico-racial, sua condição econômica, sua religiosidade. Educação com reconhecimento, sim! Integração, assimilação, não!” (p. 163).

"[...] a fim de atingir a meta de todos ou de muitos - professores e estudantes tomarem parte das deliberações, impõe-se necessariamente que, inclusive os professores, se eduquem para tanto. Como podemos educar para o que quer que seja, se somos muitas vezes deseducados, na perspectiva buscada?" (p. 167).

“[...] as diferentes instâncias da sociedade já não podem deixar de reconhecer o estado de exclusão em que vive a significativa maioria dos negros e negras brasileiros nem de tomar medidas para reverter essa situação.” (p. 170).

“[...] programas de ações afirmativas podem reverter e consolidar o lugar dos negros na sociedade, além de reconhecer e certificar seu pertencimento étnico-racial enraizado no Mundo Africano." (p. 170).

“[...] nós professores, com a presença de estudantes oriundos de grupos populares nos bancos universitários, estamos tendo que romper com procedimentos de ensino anteriormente adotados e, em muitos casos, com o alheamento da realidade em que temos construído nosso ensino. (p. 171).

Assim, Petronilha aprendeu e se tornou professora, pesquisadora e militante, fazendo da sua produção de conhecimentos e da docência instrumentos e formas de luta contra o racismo e qualquer forma de discriminação. Podemos considerar exitoso o objetivo do livro, que é inspirar as jornadas de seus leitores a partir do relato de sua trajetória de vida.

Agradecemos à professora, pesquisadora e militante Petronilha por compartilhar conosco suas lembranças e experiências, que são inspirações para nossa jornada.

\footnotetext{
${ }^{1}$ Mestranda no Programa de Pós-Graduação em Educação da Universidade Federal de São Carlos - Campus: São Carlos. E-mail: g.zielafranco@ hotmail.com

${ }^{2}$ Professor do Departamento de Educação (DEd) da UFSCar (São Carlos). Membro do HISTEDBR
} 